\title{
A TECHNIQUE FOR THE MEASUREMENT OF ERYTHROCYTE DIAMETERS
}

\author{
BY \\ G. C. ADAMS \\ From the Midwifery Department, University of Aberdeen
}

(RECEIVED FOR PUBLICATION JUNE 15, 1953)

The methods available for the measurement of red blood cell diameters can be classified under the following main headings: (1) The Price-Jones technique and its modifications ; (2) the use of an ocular micrometer ; (3) diffraction methods (Pijper, 1947) ; (4) a photographic method of Ponder and Millar (1924) in which the erythrocytes are photographed in plasma, unstained, and the measurement of the cell diameter made directly off the negative. The choice of any one of these methods is a personal one and will depend upon the type of work to be undertaken and the facilities available. Ponder and Millar (1924) state that erythrocytes measured by any of the methods using stained preparations are smaller due to shrinkage and that the difference in size of the cells is about $1 \mu$. For clinical purposes, however, and for laboratory diagnosis it is more practicable to use a method requiring a stained preparation, and of these the technique of Price-Jones (1933) is the most accurate although it is time-consuming and tedious.

In this technique, the microscope is set up in the horizontal position with the mirror removed and a point of light directed through the condenser. A prism fitted over the eyepiece of the microscope projects the image down on to the bench.

The combination of objective size, eyepiece magnification, tube length, and distance above the bench should be such that a magnification of $\times 1,000$ is obtained. This magnification is calibrated by the use of a stage micrometer, where the value is calculated in $\mathrm{mm}$. Therefore, at a magnification of $\times 1,000,1 \mu$ is equal to $1 \mathrm{~mm}$. on the projected image. The stage micrometer is then removed and a stained blood film is placed in the stage of the microscope and the images of the cells projected on to a white paper on the bench. The outlines of the cells thus projected are drawn with a pencil and the diameters measured to the nearest $0.5 \mathrm{~mm}$. The diameters of 500 cells are measured and the Price-Jones curve plotted (Whitby and Britton, 1950).
The technique described in this paper is a modisfication of the Price-Jones method.

\section{Technique}

Blood films are prepared by the orthodox methodn care being taken to produce thin, evenly spread films for subsequent staining. Leishman stain is used. The slide is flooded with stain and left for two minutes after which twice the volume of distilled water is added and mixed well with the stain. This is left fof five to seven minutes. Leishman stain is sensitive $t \theta$ any change in $p \mathrm{H}$, so that the water used in the pre paration of the stain and the dilution must have a $p \mathbb{P}$ value of between 6.6 to 6.8 . This is done by adding $2 \mathrm{ml}$. of a $\mathrm{M}-5 \mathrm{KH}_{2} \mathrm{PO}_{4}-\mathrm{NaOH}$ buffer solution to eac $100 \mathrm{ml}$. of distilled water used (Dacie, 1950).

After staining, the blood film is washed in buffered water until it assumes a bright rose-pink colour. H is then dried and the patient's name written on this actual film with a lead pencil. In practice it has been found that the tap water in this laboratory is off satisfactory $p \mathrm{H}$ value, and this is used in the preparation and dilution of the stain and final washing.

The apparatus is set up as illustrated (Fig. 1) in darkened room illuminated only by a photographis safelight (yellow), and using a stage micrometer the manner described; the magnification is adjusteg to $\times 1,000$. With the microscope lamp still on, the stage micrometer is replaced by a stained blood film and a sheet of bromide foil card (Kodak Data Book of Applied Photography, 1953) is placed on the bench in the position normally occupied by the sheet of white paper in the original Price-Jones technique. O

The image of the projected erythrocytes is focusedb critically on the foil card and the microscope lamp switched off. The foil card used for focusing is rêt moved and replaced with an unexposed sheet of fo⿺ card. The microscope lamp is switched on again for 30 to 40 seconds, then extinguished once more; th $\overline{6}$ represents a photographic exposure, and a record off the red cell images has been made on the sensitive emulsion of the bromide foil card. The length of the exposure time must be obtained by experiment but it has been found that using a lamp of the 12-vol "pointolite" type the given times are sufficient.

Bromide foil card is a photographic, sensitive emule sion on an aluminium base used when dimensiona stability is required in photographic recording. The 
Fig. 1.-The apparatus used in this method. 1, Microscope lamp. 2, Blood film in microscope stage. 3, Drawing prism fitted over eyepiece. 4, Bromide foil card on which are projected erythrocyte images.

Fig. 2.-A typical bromide foil card recording of the erythrocyte shapes.

Fig. 3.-The glass scale for measuring diameters calibrated in $\mathrm{mm}$.

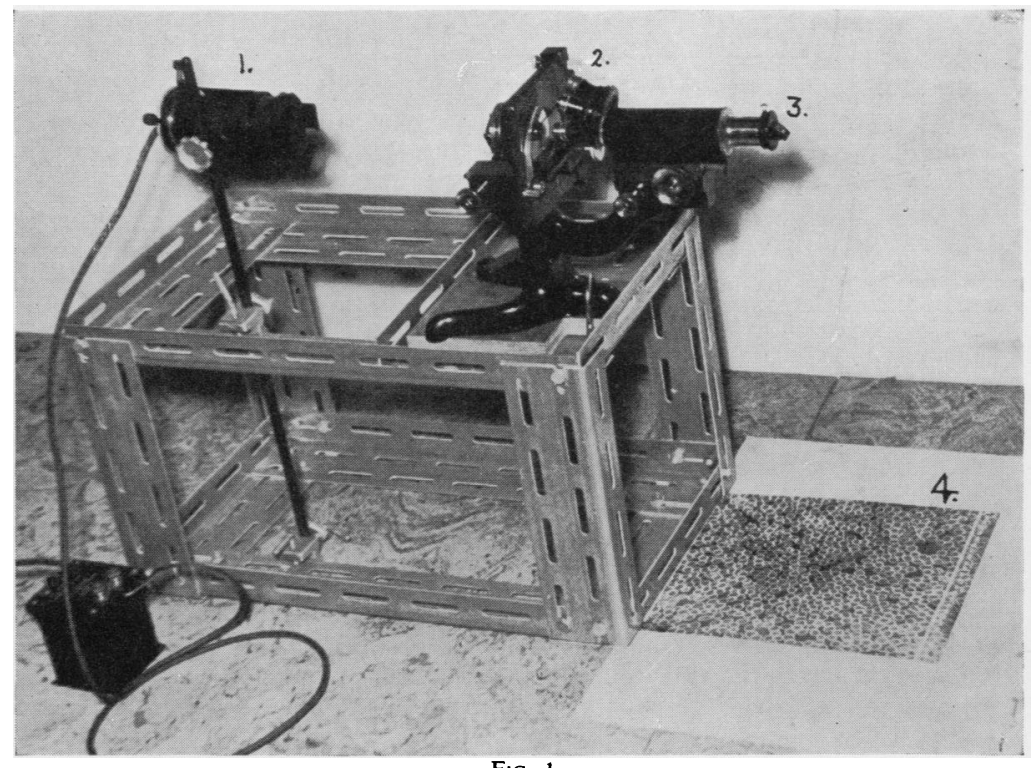

Fig. 1.

aluminium base of this material enables it to lie quite flat on the bench during exposure of the projected images, ensuring critical focus to be maintained. Also, it is not liable to shrink during subsequent pro-

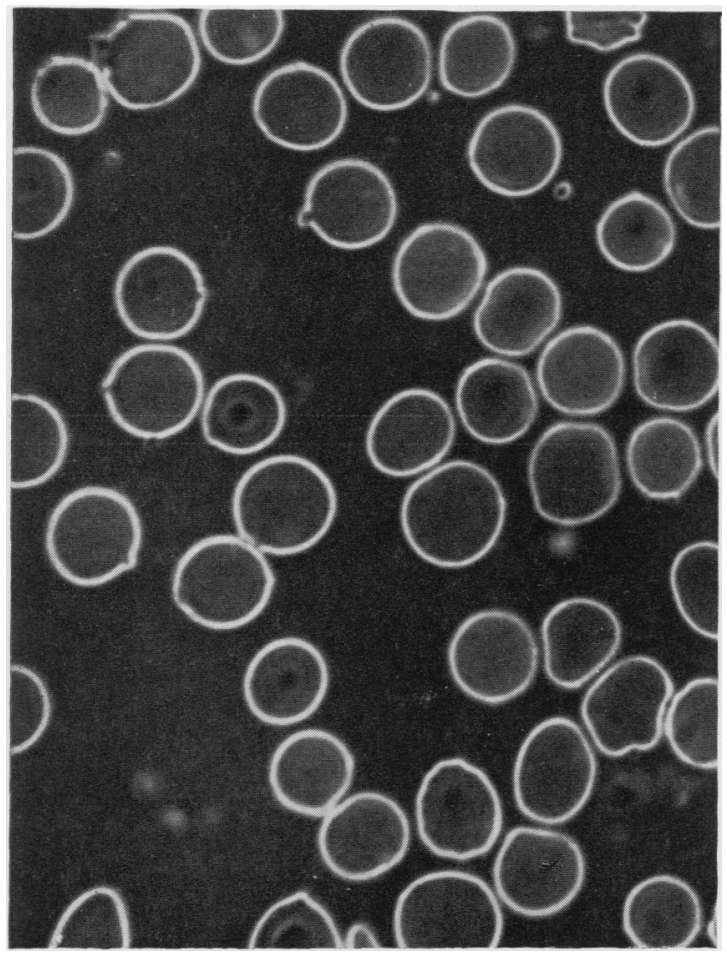

Fig. 2. cessing and washing, causing distortion of the shapes of the red cells.

The foil card is then developed in a metol hydroquinone developer to finality at $65^{\circ} \mathrm{F}$. As the re-

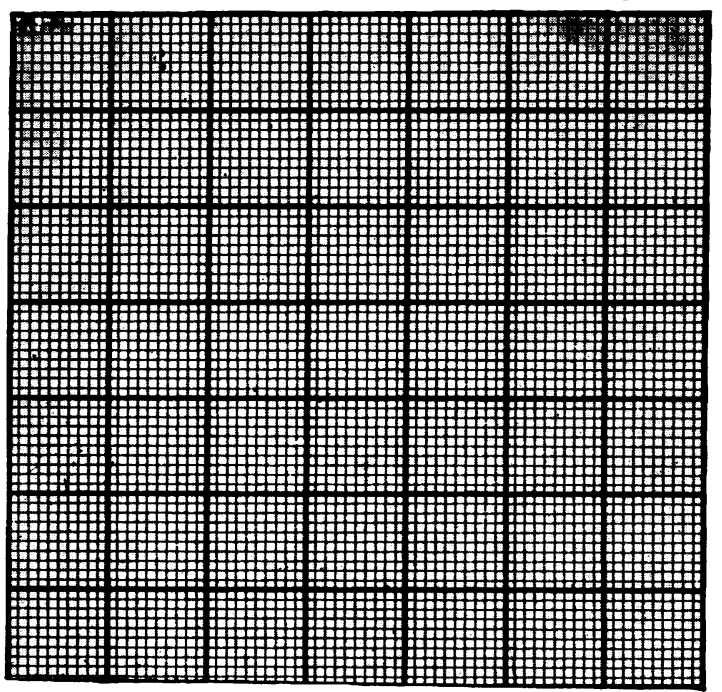

Fig. 3.

corded image is a negative one, the red cells appear white against a black background, and when development is completed the card is fixed in a hyposulphite bath, washed and dried, when it can be taken into normal lighting conditions and the cell diameters measured when convenient.

Fig. 2 shows an example of the record made in this way. 


\section{Measurements of the Red Cell Diameters}

The cell diameters are measured using a glass scale calibrated in millimetres (Fig. 3) which is placed over the cell and two readings taken at right angles, thus obtaining a mean diameter. The size of the cell diameter when measured is written inside the image of the cell on the foil card. The diameters of 500 cells, from each of three fields of the stained film, are measured and the Price-Jones curve plotted (Turnbull. unpublished data).

\section{Comment}

This technique improves on the accuracy of the original Price-Jones method because actual permanent records are made of the erythrocyte shapes, which can be checked by more than one operator. A large number of preparations can be accumulated and recorded in this way during one darkroom session, the actual measurement of the cells being left until convenient, thus eliminating the tedious process of outlining the cell images in pencil in a subdued light. The foil card records can be stored with the patient's case notes or filed with research material to be referred to at any time. Also this technique does not involve the use of special equipment other than that found in most laboratories, except for the small items of photographic equipment required to process the bromide foil cards, and a room which is capable of being darkened. The time saved by this tech 흘 nique is considerable, as dozens of fields can be recorded in the time formerly taken to outline $500 \mathrm{~B}$ cells by the original method.

\section{Summary}

A simple method of obtaining permanentw records of the shape of erythrocytes in staines preparations for subsequent measurement of theip diameters is described.

I have to thank Professor Dugald Baird for permis $\sigma$ के sion to publish this paper, also Dr. E. Turnbull foro the use of unpublished material, and Mr. R. G. MDrummond for photographs of the apparatus.

\section{REFERENCES}

Dacie, J. V. (1950). Practical Haematology. Churchill, London. Kodak Data Book of Applied Photography, Vol. 4 (1953).

Pijper, A. (1947). J. Lab. clin. Med., 32, 857.

Ponder, E., and Millar, W. G. (1924). Quart. J. exp. Physiol. 14, 67 Price-Jones, C. (1933). Red Blood Cell Diameters. Oxford Univer $A$ sity Press, London.

sity Press, London.
Turnbull, E. Unpublished data.

Turnbull, E. Unpublished data.
Whitby, L. E. H., and Britton, C. J. C. (1950). Disorders of the Blood, 6th ed. Churchill, London 